\title{
An Indicator Model of the Spatial Quantification and Pattern Analysis of Urban Sustainability: A Case Study of Cincinnati, Ohio
}

\author{
Gökçer Okumuş', David J. Edelman² \\ ${ }^{1}$ Department of Urban and Regional Planning, Faculty of Architecture, Istanbul Technical University, Istanbul, \\ Turkey \\ ${ }^{2}$ School of Planning, College of Design, Architecture, Art and Planning, University of Cincinnati, Cincinnati, USA \\ Email: okumusg@itu.edu.tr, edelmadj@ucmail.uc.edu
}

Received 13 July 2015; accepted 1 September 2015; published 4 September 2015

Copyright (C) 2015 by authors and Scientific Research Publishing Inc.

This work is licensed under the Creative Commons Attribution International License (CC BY). http://creativecommons.org/licenses/by/4.0/

(c) (i) Open Access

\begin{abstract}
Shen \& Guo (2014) have recently developed an array of urban sustainability indicators (USIs) as a tool to measure urban sustainability. Using 2006 data for Saskatoon, Saskatchewan, Canada, they developed a theoretical integrated USI model with a hierarchical index system, to spatially monitor urban sustainability using geo-matic approaches and further statistically detect its spatial patterns. The purpose of this study is to apply Shen and Guo's general approach to a major American city, Cincinnati, Ohio, utilizing U.S. census data from 2010, to test its utility beyond the original Canadian test case. In doing so, the model and its indicator structure were modified for the American context after a further review of sustainability indicators. Unlike Shen and Guo, however, the model is not subjectively weighted. Nevertheless, the revised model similarly applied both statistical analysis and geo-statistical analysis to explore how urban sustainability was spatially distributed and what spatial patterns (random, dispersed or clustered) for the indices could be found among Cincinnati's census tracts. This work confirms Shen and Guo's conclusion that geo-matic tools can be applied to detect spatially urban sustainability patterns, which can be provided visually for urban planners, managers and administrators for use in future policy making and implementation.
\end{abstract}

\section{Keywords}

Urban Sustainability, Urbanization and Quality of Life, Indicator Model, GIS, Spatial Pattern Analysis, Spatial Autocorrelation, Cincinnati 


\section{Introduction}

A recent study (Shen \& Guo, 2014) developed a number of urban sustainability indicator (USI) sets to test whether they could be used as a tool to quantitatively measure urban sustainability as had been proposed previously (Harvey, 1991). Numerous authors have written about the utility of these indicators, but have not employed a quantitative framework (McLaren, 2007; Singh et al., 2009; Tanguay et al., 2010). Using a theoretical integrated USI model with a hierarchical index system that they established and tested in earlier work (Shen, Kyllo, \& Guo, 2013), Shen and Guo attempted to spatially monitor urban sustainability using geo-matic approaches and further statistically detect its spatial patterns. The city of Saskatoon, Saskatchewan, Canada was used as a case study using 2006 data. Among their findings, they determined that the geospatial techniques of remote sensing and GIS were an excellent method to investigate urban sustainability patterns from a spatial perspective through combining multiple data sources into one geodatabase (Ibid.).

The purpose of this study, then, is to apply Shen and Guo's general approach to a somewhat larger and more complex American city, Cincinnati, Ohio, utilizing U.S. census data from 2010, to test its applicability beyond the original Canadian test case. In doing so, the model and its indicator structure were modified for the American context after a further review of sustainability indicators (Shen et al., 2011; Mori \& Christodoulou, 2012; Vojnovic, 2014). The adjusted theoretical USI framework model has the same two broad categories of Urbanization and Quality of Life (Figure 1), but has 21 urban sustainability indicators, rather than ten, in a hierarchical system. The most specific indices are at Level 1 (i.e., Density, Housing, Transportation \& Accessibility, Economic and Social Indices, etc.). Level 2 indices are more aggregated (i.e., Urbanization Index and Quality of Life Index) and the most aggregated Level 3 index is the overall Urban Sustainability Index. The Quality of Life Index, then, is calculated by adding together the Economic Well-being Index, Social Well-being Index and Environmental Well-being Index, while the Urbanization Index is the sum of the Density, Transportation \& Accessibility, Housing, Energy and Mixed Land Use Index. Unlike Shen and Guo, however, the model is not subjectively weighted in that social surveys are not conducted in relation to the Level 1 QOL indices. The Quality of Life Index and the Urbanization Index are then equally weighted. Nevertheless, the revised model similarly applied both statistical analysis and geo-statistical analysis (Moran's I global autocorrelation and Anselin Local Moran's I autocorrelation) to explore how urban sustainability was spatially distributed and what spatial patterns (random, dispersed or clustered) for the 8 indices could be found among Cincinnati's 410 census tracts in 2010 . This work confirms Shen and Guo's conclusion that the geo-matic tools can be applied to detect spatially urban

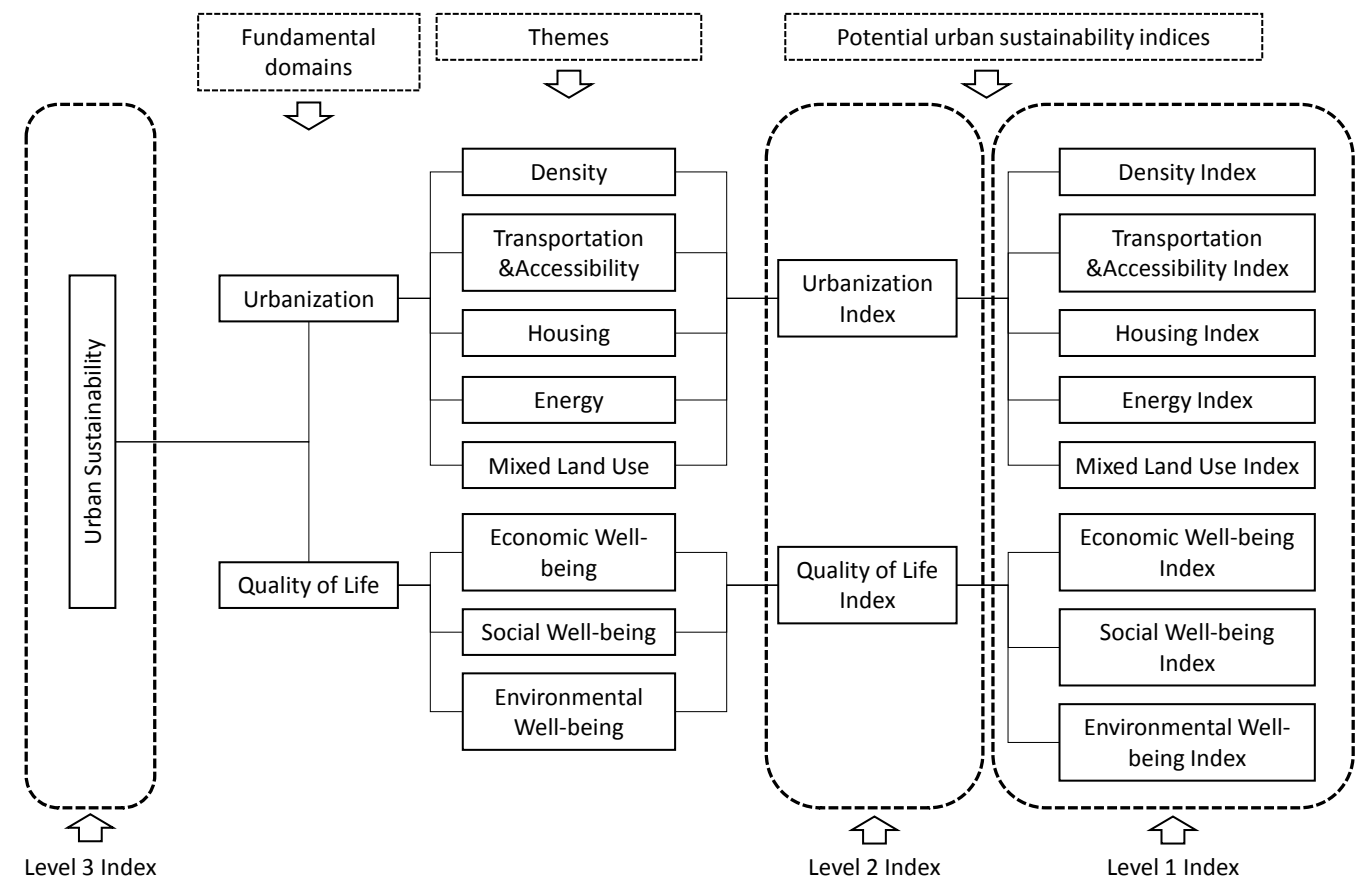

Figure 1. Urban sustainability indicator model. Source: authors. 
sustainability patterns, which can be provided visually for urban planners, managers and administrators, to minimize disparities and balance development in future policy making and implementation (Ibid.).

\section{Study Area}

Cincinnati is a major American city on the Ohio River in the Midwest. It is located in southwest Ohio, where that state meets Kentucky and Indiana. The city has a total area of 79.54 square miles $\left(206.01 \mathrm{~km}^{2}\right)$ and is the county seat of Hamilton County. The third largest city in Ohio and the $62^{\text {nd }}$ largest city in the United States, it has a population of 296,945 according to the 2010 census, while the population of the metropolitan area is 2,214,954 - the $28^{\text {th }}$ largest Metropolitan Statistical Area (MSA) in the United States and largest centered in Ohio (Scott, 2010). While the city's population has declined since World War II as residents have moved to the sprawling suburbs, the city has a diverse economy with a highly educated labor force, several major universities, a number of Fortune 500 companies (e.g., Proctor and Gamble, Macy's and Kroger), a modern international airport and relatively low living costs. This has sheltered the region from the negative impacts of recession and kept unemployment rates low. As of the 2010 census, the racial demographics for the City of Cincinnati are: 49.3\% white (48.1\% non-Hispanic white), $44.8 \%$ African-American, $0.3 \%$ American Indian or Alaskan Native, $1.8 \%$ Asian, $0.01 \%$ Hawaiian or Pacific Islander, $2.5 \%$ two or more races and $2.8 \%$ Hispanic of any race (U.S. Census Bureau Quick Facts) (http://quickfacts.census.gov). With 52 neighborhoods, the city is divided into 410 census tracts, for which 2010 census data are available, and which form the basis of analysis for this study.

\section{Materials and Methods}

\subsection{Census Data Preparation}

The census data used in this research are extracted from the U.S. Census Bureau's "American Fact Finder" web portal. This portal includes all the surveys done by the department. The 2010 American Community Survey (ACS) 5-year estimates data were compiled and combined in a database for the parts of all 3 states (Ohio, Kentucky and Indiana), which form the City of Cincinnati's metropolitan area, known formally as the Cincinnati-Middletown Metropolitan Statistical Area and informally as Greater Cincinnati. Of the 21 indicators, 14 were compiled from ACS data. Density, percentage of sustainable transportation, energy consumption and household index are calculated as composite indicators based on ACS (U.S. Census Bureau American Community Survey) (http://www.census.gov/programs-surveys/acs.html).

\subsection{Spatial Data Preparation}

The first task here was to specify the census tracts of this study of a dispersed city. The census tract boundaries and the urbanized area data, downloaded from the U.S. Census Bureau's TIGER Database (U.S. Census Bureau's MAF/TIGER Database) (https://www.census.gov/geo/maps-data/data/tiger.html), were intersected in GIS to form the study area. The data of all 410 census tracts were used to convert the tabular database into a spatial geo-database and extract the other spatial data for the whole study area.

Second, some spatial data essential for this research were taken from the spatial databases of other institutions. The land use data are from the Ohio, Kentucky and Indiana Regional Council of Governments (OKI) 2010 land use distribution data (The Ohio-Kentucky-Indiana Regional Council of Governments) (http://www.oki.org) and were intersected by census tract. The important impervious land percentage data were obtained from the United States Geological Survey (USGS) web portal, where the National Land Cover Database (NLCD) 2011 Percent Developed Imperviousness data (U.S. Geological Survey) (http://glovis.usgs.gov) were downloaded and intersected by the census tracts.

Finally, the transportation network and bus routes were taken from the OKI database, (http://www.oki.org), and grocery store locations were geocoded from the address data (Kroger Grocery Addresses)

(http://www.kroger.com). GHG emissions data for energy index was downloaded from an organization's web site called The Center for Neighborhood Technology (CNT) (The Housing and Transportation Affordability Index) (http://htaindex.cnt.org).

\subsection{Geo-Database Creation and Index Calculation}

In this research, there are 21 indicators defined in 8 level 1 indices and 2 level 2 indices defined as the Quality of 
Life Index and the Urbanization Index. These indices are mathematically aggregated to develop the level 3 Urban Sustainability Index (Figure 2).

Quality of life indicators are formed with the data extracted from the American Community Survey (ACS) database. All indicators show rates or percentages. For the aggregation, directions of values were corrected by deducting 1 for those indicators that have negative effects on the value of the Urban Sustainability Index.

Urbanization indicators were placed in 4 subgroups in terms of data preparation. Gross density, housing and sustainable transportation indicators were developed by calculating or directly using the ACS data. As composite indicators, net density, bus zone, grocery zone, park area percentages and the mixed land use index were calculated by using two or more data values. The impervious area percentage was put in a separate group because of the use of raster data from a different source. Lastly, energy consumption was defined as a composite indicator, which includes the percentage of building stock constructed before the year 2000, the percentage of households having more than 2 cars, and the percentage of low net density area.

\subsection{Spatial Classification and Pattern Analysis}

In urban planning, spatial classification is essential for a better interpretation of data and is very helpful to decision makers in developing necessary policies and implementation strategies. Mapping, especially that which shows a comparison between the units of research, i.e., census tracts, eases the interpretation of patterns. In this study, equal interval classification is implemented to demonstrate the spatial classification of 8 urban sustainability indices among the 410 census tracts in Cincinnati for the year 2010. The equal interval scheme has 5 classes ranging from 0 to 1 .

In addition to spatial classification, for the statistical analysis of the spatial patterns, both global and local autocorrelation analysis were applied. For global pattern analysis, Moran's I provides an overall evaluation of autocorrelation status. The analysis extracts 3 statistical values, which are the Moran's I index (ranging from -1.0 to 1.0), a Z-score, and a p-value. A positive value of Moran's I means that neighboring polygons (census tracts) are in a positive autocorrelation under a clustered spatial pattern. A negative value, however, means that a dispersed spatial pattern of neighboring polygons exists. The Z-score (standard deviation) should be $<-1.96$ or $>+1.96$ and the p-value (probability) is expected to be $<0.05$ to define the interpretation as statistically significant. For the local perspective of autocorrelation, the Anselin Local Moran's I is implemented to get four statistical values: Local Moran's I value, codes (HH, LL, HL, and LH), a Z-score, and a p-value. The codes refer to

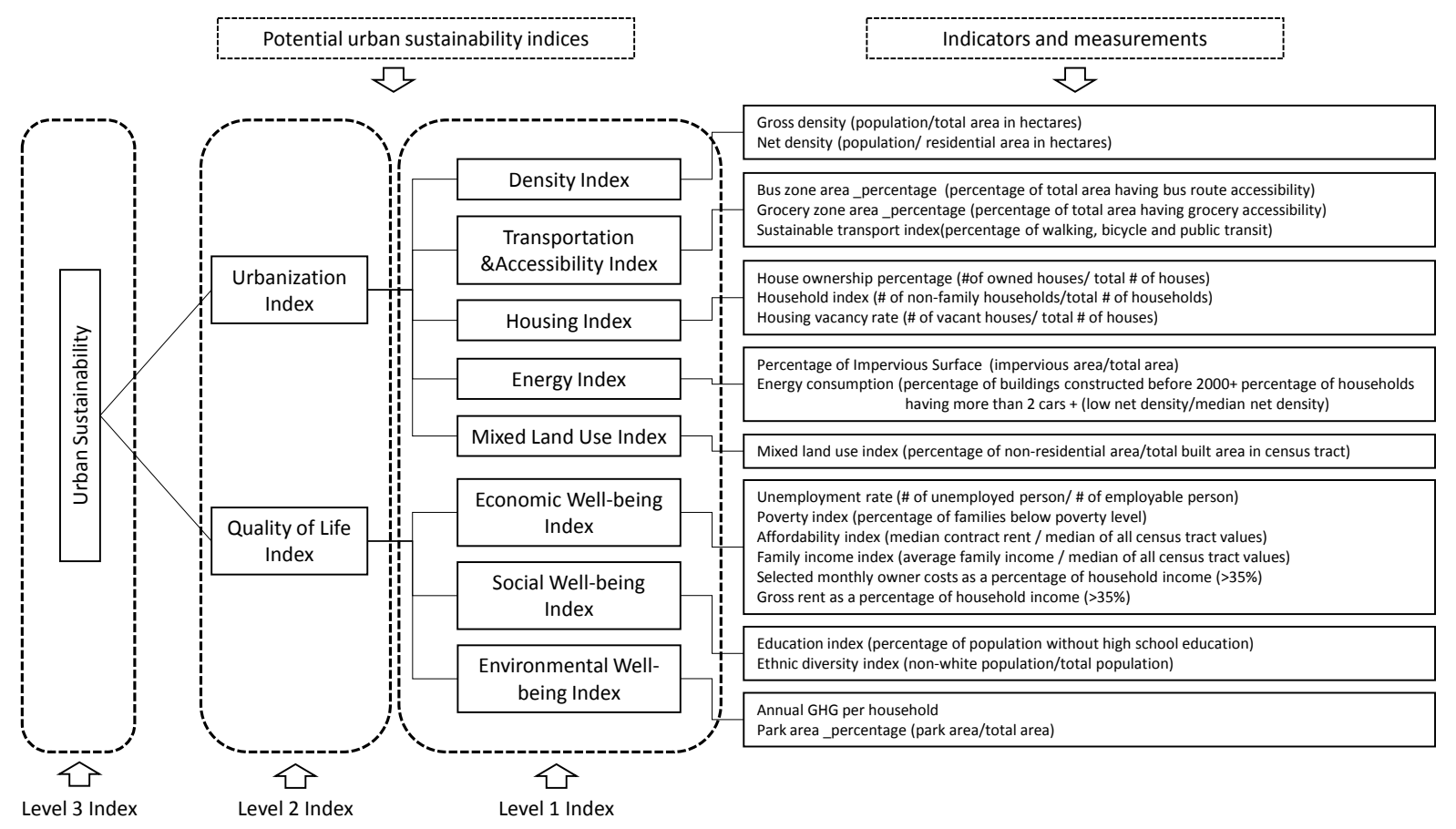

Figure 2. Description and measurements of potential USIs for the Improved USI model. Source: authors. 
Table 1. Global spatial pattern analysis (Moran's I). Source: compiled by authors.

\begin{tabular}{|c|c|c|c|c|c|}
\hline Urban Sustainability Indices & $\begin{array}{l}\text { Conceptualization of } \\
\text { Spatial Relationships }\end{array}$ & $\begin{array}{l}\text { Moran's } \\
\text { I Index }\end{array}$ & $\begin{array}{l}\text { Z-Score (Significant } \\
\text { at the } 0.05 \text { Level) }\end{array}$ & $p$-Value & $\begin{array}{c}\text { Global Spatial } \\
\text { Pattern }\end{array}$ \\
\hline Density Index & Contiguity Edges and Corners & 0.54 & 19.56 & 0 & Clustered \\
\hline Transportation \& Accessibility Index & Contiguity Edges and Corners & 0.74 & 26.27 & 0 & Clustered \\
\hline Housing Index & Contiguity Edges and Corners & 0.67 & 24.03 & 0 & Clustered \\
\hline Energy Index & Contiguity Edges and Corners & 0.37 & 13.4 & 0 & Clustered \\
\hline Mixed Land Use Index & Contiguity Edges and Corners & 0.31 & 11.34 & 0 & Clustered \\
\hline Economic Well-being Index & Contiguity Edges and Corners & 0.31 & 11.15 & 0 & Clustered \\
\hline Social Well-being Index & Contiguity Edges and Corners & 0.55 & 19.78 & 0 & Clustered \\
\hline Environmental Well-being Index & Contiguity Edges and Corners & 0.66 & 23.69 & 0 & Clustered \\
\hline QOL Index & Contiguity Edges and Corners & 0.17 & 6.43 & 0 & Clustered \\
\hline Urbanization Index & Contiguity Edges and Corners & 0.55 & 19.76 & 0 & Clustered \\
\hline Urban Sustainability Index & Contiguity Edges and Corners & 0.4 & 14.36 & 0 & Clustered \\
\hline
\end{tabular}

cluster types. $\mathrm{HH}$ is a cluster of high values, while LL is a cluster of low values. HL represents a high index value outlier surrounded by low index values, and LH represents a low index value outlier surrounded by high index values. Table 1 describes the results of the Moran's I analysis of this study's Urban Sustainability Indices.

The results of the Moran's I analysis of all level indices show that all values are in the desired range. When running the analysis, "contiguity edges and corners" was selected as the conceptualization of spatial relationships. Given the Z-score of all indices, there is a less than $1 \%$ likelihood that this clustered pattern could be the result of random chance. This result proves the reliability of the study.

\section{Results and Discussion}

In this study, indices at all levels are mapped for interpretation of urban sustainability in the City of Cincinnati. Five equal classes are used with the same color scheme to compare all levels in terms of high or low values. For interpretation, the Greater Cincinnati is divided into 3 major zones; i.e., the "inner core" defined as downtown and adjacent areas, the "inner ring" defined as the area between downtown and the loop highway I-275, and the "outer ring" defined as the areas that are outside the I-275 loop.

Beginning with the Level 1 indices (Figure 1), the Density Index is calculated by aggregating standardized gross density and net density values. The last index value is also standardized before mapping. It demonstrates (Figure 3) that higher index values are located in the inner core, mid-range values in the inner ring and low values in the outer ring. This situation represents most of the American cities that have developed as mono-centric. The Transportation \& Accessibility Index map shows that higher values are located especially in the inner core, but also in the inner ring as an effect of bus routes and groceries being located at the loop junctions. However, this index, which is defined as sustainable transportation, percentage of walking, cycling and public transport, has quite low values in the outer ring, as would be expected. As a combination of household type, house ownership and housing vacancy rate, Housing Index values are low in the inner core and the surrounding areas of work zones. The outer ring has higher values, although the inner ring has a mixed pattern. The Energy Index is also a combined index, which includes the percentage of buildings built before the year 2000, a car ownership rate having more than 2 cars and low density values divided by median low density values. This resulted in low index values, especially in the inner core, due to the age of buildings. In the outer ring, the values are high as a representation of low density and high car ownership (Figure 3).

The Mixed Land Use Index map in Figure 4 illustrates higher values in the northern work zones around the loop. However other areas have low values. The Economic Well-being Index is calculated as a combination of 6 indicators, and its map represents a mixed pattern of the highest values located in the inner ring, while the lowest values are located in the inner core and nearby work zones. The map of the Social Well-being Index demonstrates the racial segregation problem in American cities in that high diversity value areas are also low education areas, and these areas are located in the inner ring. The last index of the level 1 indices, the Environmental Well-being Index indicates that the inner core and inner ring have higher values, while the outer ring has lower 

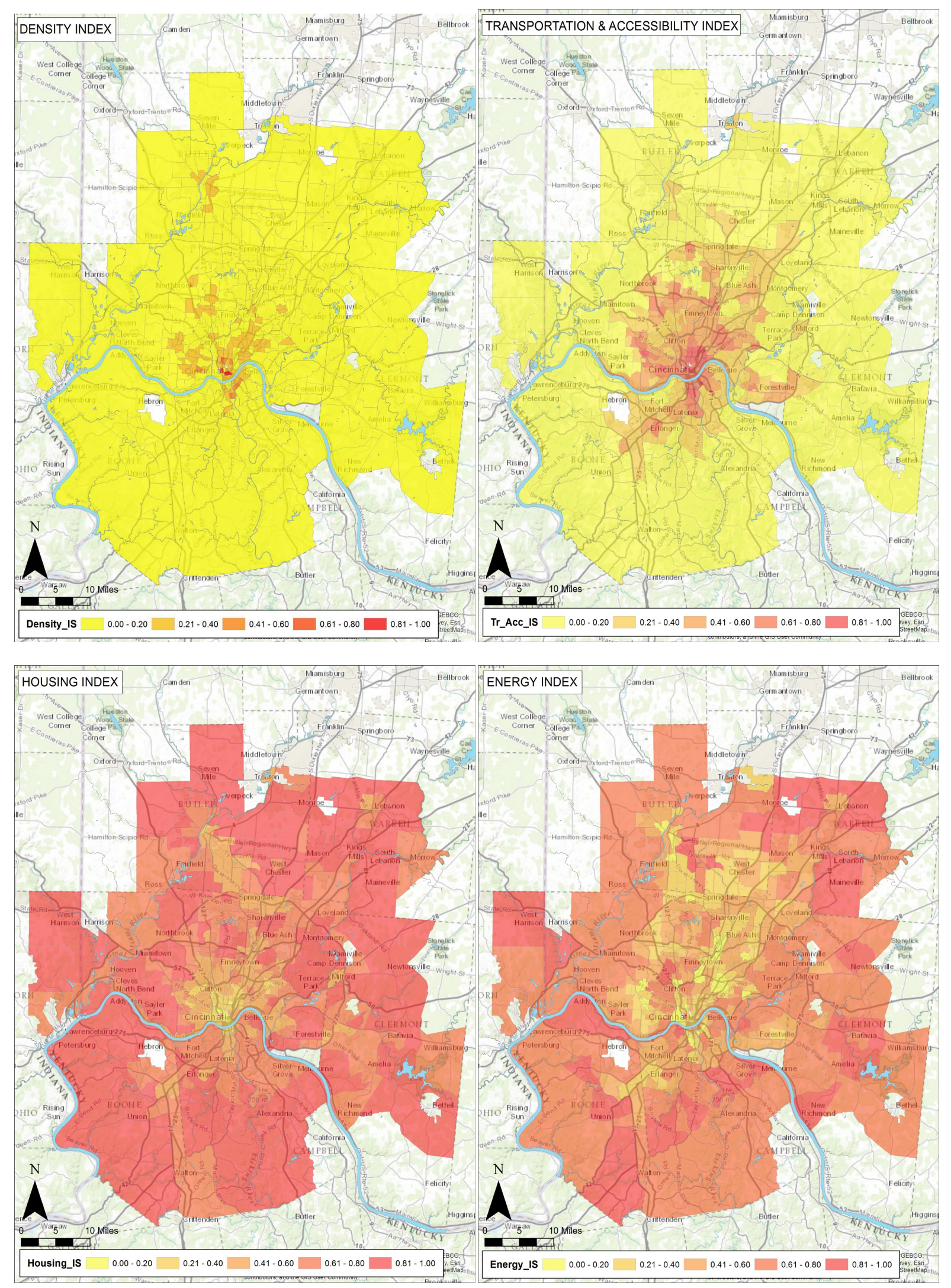

Figure 3. Density, transportation \& accessibility, housing and energy indices. Source: authors. 

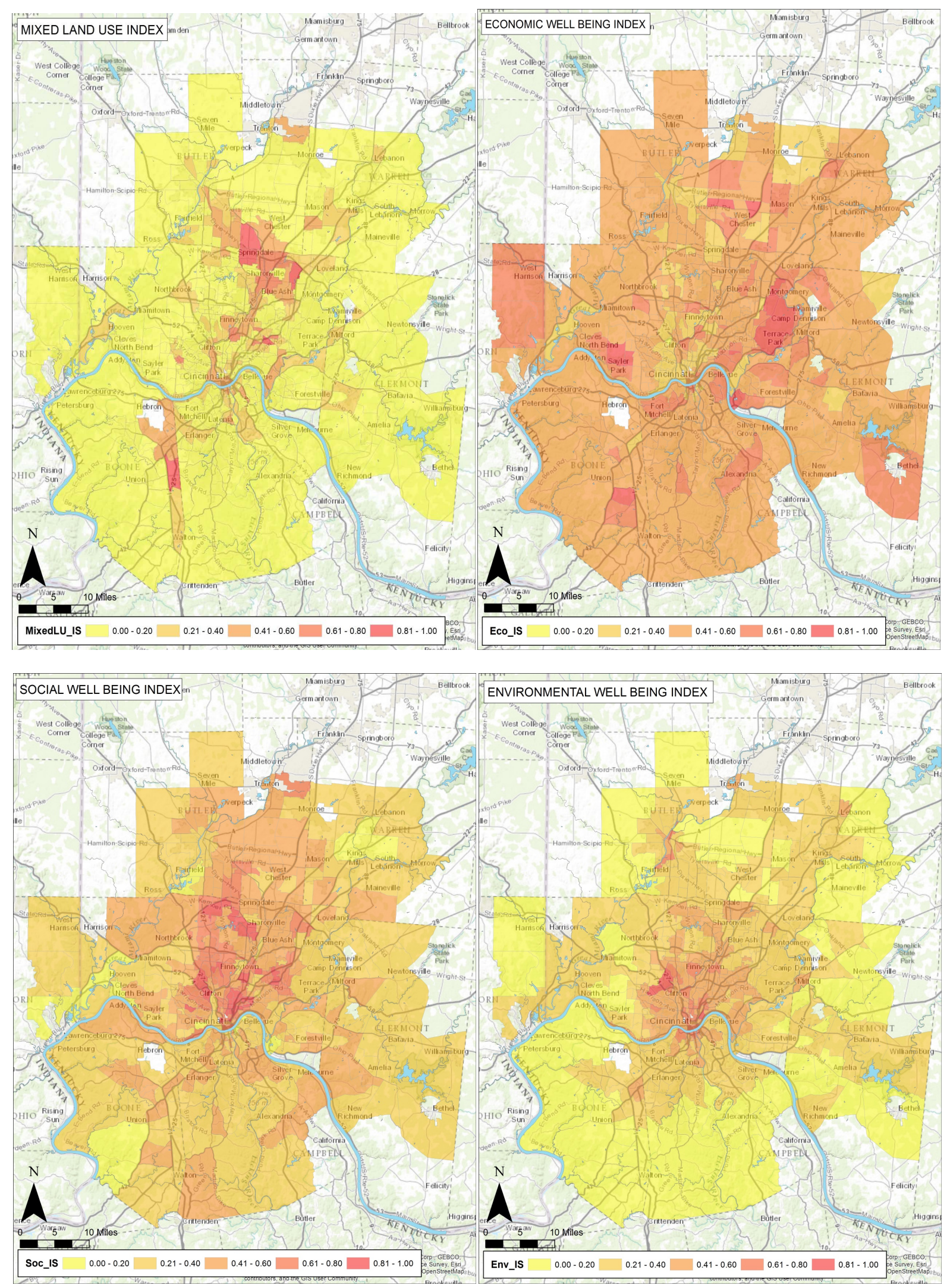

Figure 4. Mixed land use, economic, social and environmental well-being indices. Source: authors. 

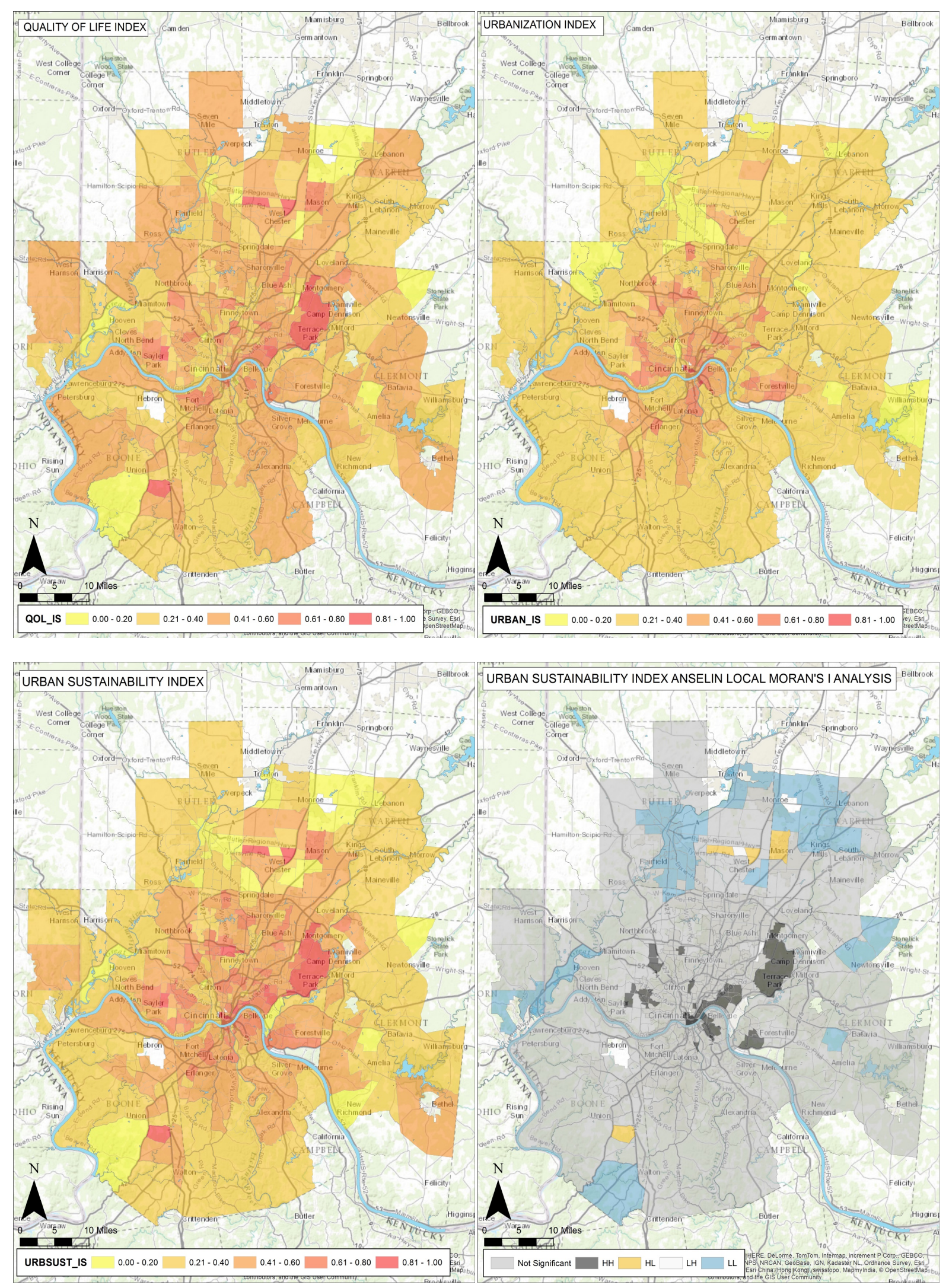

Figure 5. Quality of life, urbanization, urban sustainability indices and Anselin Moran's I analysis. Source: authors. 
values (Figure 4). This shows that Cincinnati's parks comprise a much higher percentage of total land area within the I-275 loop, perhaps showing less that the parks closer to the urban core are larger, but more that houses farther out have far larger plots, thus making the acreage in parks a much smaller percentage of total land area.

Level 2 indices are the aggregation of level 1 indices, assuming all have equal weights. The map of the first level 2 index, Quality of Life, shows that high values are located in the inner ring. However, low and mid-range values are spread all over the city, in particular due to economic factors. The Urbanization Index map demonstrates that the inner core and surrounding areas have high values, while the inner ring has mid-range values and the outer ring has low values. The higher values are the result of higher density and the presence of more urban amenities.

The last level of analysis is represented by the level 3 index of Urban Sustainability. This index map shows that higher values are located in the inner ring and inner core areas, although there are also some isolated high values in the outer ring where there are high mixed land use values. The Anselin Moran's I analysis calculated with these index values shows that clusters of high values are located in the inner core and inner ring, while low value clusters are located in areas of the outer ring (Figure 5).

\section{Conclusion}

There are a number of conclusions that can be drawn from this study. The first is that this work confirms Shen and Guo's conclusion that geo-matic tools can be applied to detect spatially urban sustainability patterns, which can be provided visually for urban planners, managers and administrators to use in future policy making and implementation. Their study of Saskatoon has been substantiated by this study of Cincinnati. Thus, the work of both studies provides an urban policy tool that can be used in both Canada and the United States.

Second, the overall results for Cincinnati show that Urban Sustainability is highest in the inner ring and inner core areas, although there are also some isolated high values in the outer ring. Moreover, clusters of high values are located in the inner core and inner ring as well, while low value clusters are located in areas of the outer ring. These findings are due to the aggregation of both the Quality of Life and Urbanization Indices. For the former, high values are located in the inner ring, while low and mid-range values are spread all over the city. For the Urbanization Index, the inner core and surrounding areas have high values, while the inner ring has mid-range values and the outer ring has low values. Thus, the 2 level 2 indices reinforce each other to produce the Urban Sustainability Index for Cincinnati.

Finally, the policy implications for these findings are not surprising, and they support conclusions drawn by many observers from other sources. However, the work done here enables decision-makers to formulate policies to increase urban sustainability in Cincinnati by directing them spatially, supported by statistical analysis, to the areas of the city where they will do the most good. Such directed policies have the potential to save money and produce better results. Thus, increased density, more and better public transport, increased walking and cycling, a reduction in impervious surfaces (for example, especially mall and industry parking lots), higher energy efficiency of buildings and a reduction in auto trips would raise the Urban Sustainability Index in the outer ring substantially and in the inner ring to a lesser, but still noticeable, to an extent. Policies throughout the city outside the urban core would increase ethnic diversity and an improved local economy would benefit the city overall.

Additional research could refine the tool further. Applying it to other similar American cities such as Pittsburgh or Indianapolis, and then to much larger and far more complex cities such as Chicago or Houston would produce a body of results for further comparison. In addition, testing the methodology by actual application to a particular policy decision that would foster urban sustainability in Cincinnati could prove particularly fruitful.

\section{Acknowledgements}

This study was supported by the Scientific and Technological Research Council of Turkey (TUBITAK) 2214-A Fellowship Program.

\section{References}

Harvey, L. D. D. (1991). The Role of Municipalities in Combating Global Warming. Eco Decision, 3, 74-76.

Kroger Grocery Addresses http://www.kroger.com 
Mori, K., \& Christodoulou, A. (2012). Review of Sustainability Indices and Indicators: Towards a New City Sustainability Index (CSI). Environmental Impact Assessment Review, 32, 94-106. http://dx.doi.org/10.1016/j.eiar.2011.06.001

Scott, T. G. (2010). Census: Cincinnati 62nd Largest US City. Business Courier, June 22, 2010.

Shen, L., \& Guo, X. (2014). Spatial Quantification and Pattern Analysis of Urban Sustainability Based on a Subjectively Weighted Indicator Model: A Case Study in the City of Saskatoon, SK, Canada. Applied Geography, 53, 117-127. http://dx.doi.org/10.1016/j.apgeog.2014.06.001

Shen, L., Kyllo, J. M., \& Guo, X. (2013). An Integrated Model Based on a Hierarchical Indices System for Monitoring and Evaluating Urban Sustainability. Sustainability, 5, 524-559. http://dx.doi.org/10.3390/su5020524

Shen, L., Ochoa, J. J., Shah, M. N., \& Zhang, X. (2011). The Application of Urban Sustainability Indicators-A Comparison between Various Practices. Habitat International, 35, 17-29. http://dx.doi.org/10.1016/j.habitatint.2010.03.006

The Housing and Transportation Affordability Index http://htaindex.cnt.org

The Ohio-Kentucky-Indiana Regional Council of Governments http://www.oki.org

U.S. Census Bureau American Community Survey http://www.census.gov/programs-surveys/acs.html

U.S. Census Bureau Quick Facts http://quickfacts.census.gov/qfd/states/39/3915000.html

U.S. Census Bureau's MAF/TIGER Database https://www.census.gov/geo/maps-data/data/tiger.html

U.S. Geological Survey http://glovis.usgs.gov

Vojnovic, I. (2014). Urban Sustainability: Research, Politics, Policy and Practice. Cities, 41, 530-544.

http://dx.doi.org/10.1016/j.cities.2014.06.002 